\title{
Diagnóstico psiquiátrico: um guia
}

\author{
Otávia Regina Souza Costa 1
}

Nogueira, M. J. (Org.). (2002). Diagnóstico psiquiátrico: um guia. São Paulo: Lemos, 316 p.

O psicodiagnóstico é um processo de coleta de informações que visa não só ao conhecimento da história pregressa da pessoa, mas também à identificação do problema para melhor adaptação de um programa de intervenção, tanto no sentido preventivo quanto curativo. Por isso a importância da obra aqui resenhada, Diagnóstico psiquiátrico: um guia, escrita por cinco docentes de psicologia e psiquiatria, com amplo conhecimento do comportamento humano, e um acadêmico, do 6o ano de medicina, que atuou também como colaborador e elemento facilitador para que a obra não perdesse seu objetivo principal: um livro que atenda as dificuldades dos jovens profissionais e estudantes da área do comportamento humano. Conforme afirma o seu organizador, o médico psiquiatra Marcos de Jesus Nogueira,

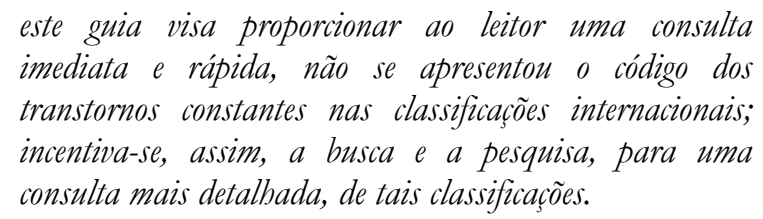

O livro utiliza como referência a Classificação Internacional da Organização Mundial de Saúde (OMS) - a CID-10 (Transtornos Mentais e de Comportamento), o DSM-IV da Associação Psiquiátrica Americana (APA) e outras obras contidas no referencial bibliográfico.

A introdução do livro é feita pelo docente da Universidade Federal de Minas Gerais, o médico José Raimundo da Silva Lippi. Comenta, de forma abrangente e objetiva, a história da Classificação das Doenças Mentais, desde o final do século XVIII, com Pinel, até a CID-10 na sua $10^{\text {a }}$ revisão e, ainda, analisa a dificuldade de coincidir a classificação das patologias com a etiologia e os quadros clínicos apresentados pelos pacientes.

$\mathrm{O}$ guia consta de sete capítulos. O primeiro trata dos Transtornos mentais predominantemente decorrentes de fatores orgânicos (demências, transtornos decorrentes de perturbações fisiológicas, cerebrais e gerais); o segundo, dos Transtornos mentais predominantemente hereditários $e$ constitucionais (esquizofrenia e outras psicoses afins, transtornos do humor, transtornos de personalidade); o terceiro, capítulo dos Transtornos mentais predominantemente decorrentes de conflitos psíquicos (transtornos neuróticos, dissociações, conversões, transtornos de controle dos impulsos, transtornos com repercussões predominantemente somáticas e com repercussões na fisiologia normal, transtorno do sono, transtornos sexuais); o quarto, capítulo dos Transtornos mentais decorrentes de fatores exógenos (transtornos relacionados ao estresse grave e moderado, transtornos relacionados ao uso de drogas, álcool, tabaco, estimulantes, alucinógenos, e outros); o quinto, capítulo dos Transtornos da infância e adolescência (transtornos invasivos do desenvolvimento, transtorno da aprendizagem, transtorno da comunicação, transtorno de conduta e emoção, e outros); o sexto, capítulo do Retardo mental (retardo mental leve, moderado, grave e profundo) e o sétimo capítulo, dos Transtornos mentais especiais (síndrome de Munchausen, transtornos mentais culturais).

Há uma legenda com todas as siglas utilizadas na obra, por exemplo, TC - tomografia computadorizada ou AVC - acidente vascular cerebral; um glossário fornecendo as definições das palavras técnicas contidas no livro, como diaforese - suor abundante, alexia - perda da capacidade de aprender o significado da palavra escrita. Em anexo há o CID - 10 para consulta.

A novidade do guia fica por conta dos recursos pedagógicos usados na apresentação dos transtornos, a linguagem sucinta, de fácil assimilação, com charges bem humoradas de Camilo Riani, que descreve as manifestações comportamentais dos pacientes, chamando a atenção para o que há de mais importante na patologia. Por exemplo, a anorexia nervosa foi ilustrada com uma mulher macérrima na frente do espelho pensando: “... Há 3 meses não menstruo...” e o que está refletido no espelho é essa mesma mulher muito gorda. O transtorno de ansiedade generalizada é representado por uma mulher com a fisionomia e o corpo tenso e três balões acima da cabeça: o primeiro contém duas crianças pulando; o segundo, com um computador repleto de papéis acumulados; e o terceiro, com o saldo bancário. A visualização desses comportamentos nas representações ilustrativas das doenças auxilia a memorização e, por outro lado, torna o texto mais atrativo para a leitura.

Outro recurso também interessante é a utilização de ícones colocados à margem esquerda do livro, os quais funcionam como sinalizadores do que se deseja saber sobre o assunto. Por exemplo, no ícone

Endereço para correspondência:

${ }^{1}$ E-mail: otaviacosta@hortmail.com 
Perigo são descritos os riscos imediatos e principais complicações de cada doença; no ícone Descobrindo são apresentadas informações importantes para o diagnóstico diferencial. Há mais três: o ícone $O$ que é oferece a conceituação do transtorno, o ícone Laboratório mostra como fazer a pesquisa laboratorial e o ícone Fique de olho apresenta os dados técnicos, históricos e outros.
O diagnóstico psiquiátrico cumpre com eficiência o objetivo de ser um guia, por utilizar uma comunicação sem mistérios e recursos pictóricos, que conduz o leitor à compreensão da conduta humana, norteando principalmente estudantes e profissionais do comportamento na busca de informações fidedignas para a realização de uma das condutas diante de um problema que necessita ser solucionado - o psicodiagnóstico.

Sobre a autora:

Otávia Regina Souza Costa é psicóloga, mestranda do Programa de Estudos Pós-Graduados em Psicologia da Universidade São Francisco e professora da Universidade Antônio Carlos, Minas Gerais. 